International Journal of Tropical Medicine 7 (3): 98-102, 2012

ISSN: $1816-3319$

C) Medwell Journals, 2012

\title{
Survey of Feline Influenza and Feline Leukemia Virus Infection in Local Breed Cats of Bangladesh
}

\author{
${ }^{1,3}$ Md. Aminul Islam, ${ }^{1}$ M. S. Rahman, ${ }^{2}$ S.A. Rony, ${ }^{1,4}$ M.J. Uddin, ${ }^{1,3}$ A.K.M.A. Rahman, \\ ${ }^{1}$ M.T. Islam and ${ }^{1,4} \mathrm{M}$. Ariful Islam \\ ${ }^{1}$ Department of Medicine, ${ }^{2}$ Department of Parasitology, Faculty of Veterinary Science, \\ Bangladesh Agricultural University, 2202 Mymensingh, Bangladesh \\ ${ }^{3}$ Institute of Tropical Medicine, Antwerp, Belgium \\ ${ }^{4}$ Animal Breeding and Husbandry Group, Institution of Animal Science, \\ University of Bonn, Bonn, Germany
}

\begin{abstract}
Feline Influenza Virus (FInV) and Feline Leukemia Virus (FeLV) are two important viruses causing cat flu and neoplastic disease all over the world, respectively but to the knowledge, there is no epidemiological survey report available for these two killer diseases in cat in Bangladesh. Therefore, the present study was aimed to determine the prevalence of FInV and FeLV infection through an epidemiologic survey in selected areas of Bangladesh. For this purpose, a total 60 randomly selected cats consisting of 48 pet and 12 stray cats at Tangail district in Bangladesh during May to October, 2009 were used. Nasal swab and blood sample were collected from all cats and tested by commercial rapid RapiGEN ${ }^{\circledR}$ Feline Influenza Virus (FInV) Ag Test kit and RapiGEN ${ }^{\circledR}$ Feline Leukemia Virus (FeLV) Ag Test kit, respectively following the manufacturer's (RapiGEN Inc., Korea) instructions. Results revealed the overall prevalence of feline influenza and feline leukemia recorded 5.0 and $1.67 \%$, respectively in cats. There was no significant relationship between the diseases (FInV and FeLV) and different variables. However, the knowledge of the status of FInV and FeLV in cats in the study area will be helpful to undertake preventive measures for FInV and FeLV infection.
\end{abstract}

Key words: Prevalence, feline influenza, feline leukemia, cats, rapid test

\section{INTRODUCTION}

Feline Influenza Virus (FInV) and Feline Leukemia Virus (FeLV) are two important viruses causing cat flu and neoplastic disease all over the world, respectively. American Association of Feline Practitioners (AAFP) recommends that the retrovirus status of all cats should be known and has published guidelines for retrovirus testing and management (Levy et al., 2008).

Feline influenza also known as feline rhinotracheitis or feline coryza is caused by feline herpes virus-1 which is found worldwide and responsible for one-half of the respiratory diseases in cats (Carter et al., 2006). Viral respiratory diseases in cats caused by feline influenza can be serious, especially in catteries and kennels (Mackenzie, 2007). Adult cats are easily infected but kittens are particularly susceptible to the illness. Like its human equivalent, feline influenza is highly contagious and easily transmitted by sneezing and coughing. The virus is shed in saliva and eye and nasal secretions and can also be spread by fomites. Feline Virus Rhinotracheitis (FVR) has a 2-5 days incubation period and the virus is shed for 1-3 weeks postinfection (Stephen et al., 1995). For cats that have not been vaccinated, feline influenza is very dangerous since, in the absence of vaccines cats have great difficulty making a full recovery and the illness can lead to chronic coryza and death (Carter et al., 2006).

Feline Leukemia Virus (FeLV) is a single-stranded, gammaretrovirus which is the leading cause of disease and death of cats worldwide. There are three types of feline leukemia virus: FeLV-A, FeLV-B and FeLV-C and cat can be infected with one, two or all three types. The virus is of outstanding interest for veterinary as well as for human medicine which is first described by Jarrett et al. (1964) as a causative agent for feline lymphosarcoma. Subsequent research revealed exogenous horizontal FeLV infection is responsible for a broad spectrum of neoplastic and non-neoplastic diseases (Cotter, 1998) and more frequently leads to an immunosupression making cats more susceptible to other diseases (Hardy and McClelland, 1977). Clinical signs of an infection with FeLV are anemia an AIDS-like syndrome and less frequently lympho-myeloproliferative or neurologic disorders (Hardy, 1980). The virus is fragile and sensitive to ordinary household detergent, heat, drying and does not survive in the environment for long time. The major mode of transmission for FeLV is through saliva, milk, blood and

Corresponding Author: Md. Aminul Islam, Department of Medicine, Faculty of Veterinary Science, Bangladesh Agricultural University, 2202 Mymensingh, Bangladesh 
urine, both vertically and horizontally whereas free-roaming cats act as reservoirs for FeLV which pose threats to the health of outdoor pet cats (Lee et al., 2002).

Rapid diagnoses of feline viral infections, especially of FInV and FeLV are important in order to isolate infected cats and prevent secondary infections of susceptible animals. Since, laboratory diagnosis requires skilled personnel, specialized equipment and laboratory as well clinical diagnosis would be the choice however, clinical diagnosis is not definitive. The immunochromatography assay is the most rapid field diagnostic method used in clinical practice because the test procedure is simple and can be performed by veterinarians as well as by pet owners (Mosallanejad et al., 2009).

Although, information on prevalence of feline viral diseases are available elsewhere in the world (Addie $e t$ al., 1998; Cave et al., 2002; Mackenzie, 2007) but to the best of the knowledge there are no inland reports on these two diseases in cats of Bangladesh. Therefore, the present research was undertaken to know the prevalence of feline influenza and feline leukemia infection in local breed cats of Tangail district in Bangladesh.

\section{MATERIALS AND METHODS}

Study area, period and animals: A cross-sectional study was conducted on a total of 60 cats ranged between 2 and 14 months of age consisted of 48 pet cats and 12 stray cats from seven villages of Ghatail upazila under Tangail district in Bangladesh during the period from April to September, 2009. None of the cats had any history of vaccination against feline viral diseases.

Test kits: Two commercially available one-step rapid antigen detection test kits namely rapid RapiGEN ${ }^{\circledR}$ Feline Influenza Virus (FInV) Ag test kit and RapiGEN ${ }^{\circledR}$ Feline Leukemia Virus (FeLV) Ag test kit (RapiGEN Inc., Korea) were used for this study. These kits are chromatographic immunoassay for the qualitative detection of feline Influenza virus antigen in nasal secretions and feline Leukemia virus antigen in blood of cats.

Collection of samples: Before sampling stray cats were controlled by trapping and pet cats by the owner. Blood samples were collected without any anticoagulant by venipuncture of jugular vein taking aseptic measures. Sera were separated and stored at $-20^{\circ} \mathrm{C}$ until tested. Nasal swabs were collected by using sterile cotton swab provided with kit and kept in top-off extraction bottles containing assay buffer and mixed properly and stored at $4^{\circ} \mathrm{C}$ until tested.

Test procedure: Both tests were performed within 7 days of sample collection in the laboratory of Department of
Medicine, Faculty of Veterinary Science, Bangladesh Agricultural University, Mymensingh following the manufacturer's instructions. Before testing, both sera and nasal swab samples were kept at room temperature for at least $30 \mathrm{~min}$ and mixed properly by stirring. In brief for FeLV four drops of supernatant from respective extraction buffer bottle were poured into the sample well (S) and for FInV one drop of serum was added into the sample well (S). As the test began to work, a purple colour band was observed moving across the result window in the center of the test device. Interpretations of test results were also performed within 4-5 min.

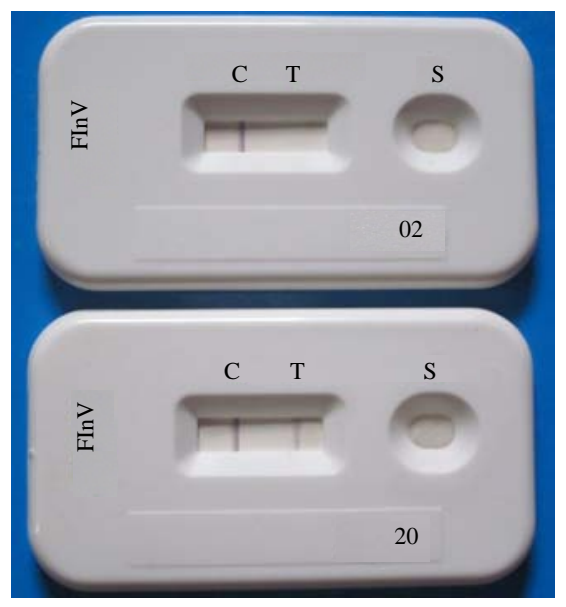

Fig. 1: Results of Feline Influenza Virus (FInV) Ag detection test showing one only band (upper one, 02) indicating negative test and showing both control and test bands (lower one, 20) indicating positive test

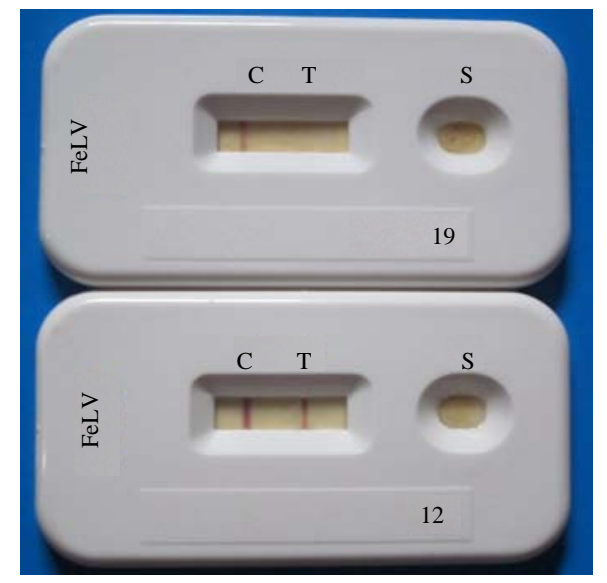

Fig. 2: Results of Feline Leukemia Virus (FeLV) Ag detection test showing one only band (upper one, 19) indicating negative test and showing both control and test bands (lower one, 12) indicating positive test 
The appearance of only one band (control band, C) within the result window indicated a negative result while appearance of two bands (test band, $\mathrm{T}$ and control band, C) within the result window, no matter which band appeared first, indicated positive result (Fig. 1 and 2). If the control band (C) was not visible within the result window after performing the test, the result was considered invalid.

Statistical analysis: Potential association of the test results with age, sex, rearing systems were performed by SPSS 11.5 in 2002 for windows using Chi-square analysis were a $p$-value of $p<0.05$ was considered as significant.

\section{RESULTS AND DISCUSSION}

Of 60 cats tested, 3 were showed positive reaction with RapiGEN ${ }^{\circledR}$ Feline Influenza Virus (FInV) Ag test yielding $5.0 \%$ prevalence of FInV (Table 1). Among three FInV positive cases, one was in cat with $>1$ year of age, apparently healthy male stray cat whereas two were female and they were aged in between 2 months to 1 year. Among all cats tested, only one apparently healthy female pet cat of $>1$ year old showed positive reaction with RapiGEN ${ }^{\circledR}$ Feline Leukemia Virus (FeLV) Ag test yielding the prevalence rate of $1.67 \%$ (Table 1 ). There was no significant relationship between the diseases (FInV and FeLV) and different variables.

The prevalence of feline influenza was recorded in this study as $5.0 \%$. Findings of the current study is comparable with Julia et al. (2008) who reported the prevalence of Influenza A virus in cat between 0.0 and $<1.8 \%$. Bulter (2006) and Mackenzie (2007) also reported that a higher percentage of cats in Asia may carry antibodies to type A influenza virus. A better understanding of the behavior of domestic cats and the type A influenza virus can be used to predict epidemic dynamics of the virus and to develop effective strategies to prevent virus transmission to both cats and humans.

The sero-prevalence of FeLV observed in this study was $1.67 \%$ which is consistent with the findings of Malik et al. (1997) who reported the range of seroprevalence of $\mathrm{FeLV}$ in pet cats varies from $0-2 \%$ in Sydney. A higher seroprevalence $(18 \%)$ of FeLV was reported in sick cats in Italy by Bandecchi et al. (1992). Hosie et al. (1989) reported the prevalence of antibodies to FeLV as $16 \%$ of 1204 sick cats and $5 \%$ of 1007 healthy household cats in UK. Other reports on prevalence of FeLV infection in cats were recorded as $0.0 \%$ in South Vietnam (Nakamura et al., 1999), 1.0\% in Finland (Sukura et al., 1992), 1.2\% in Norway (Ueland and Lutz, 1992) and 3.4\% in Canada (Little et al., 2009). Fromont et al. (2000) found a significant relationship between FeLV status and two parameters of body condition with FeLV-positives cats being in poorer condition than the FeLV-negative cats. Findings of Arjona et al. (2000) seems to indicate that sex may somehow influence the development of signs related to FeLV infection in cats who reported a significantly $(\mathrm{p}<0.05)$ higher prevalence of FeLV infection in male $(63.2 \%)$ than that of female (41.4\%). Little et al. (2009) studied several factors with risk of FeLV infection in cat and concluded that adult cats were significantly more likely $(\mathrm{p}<0.001)$ to be seropositive $(4.43 \%)$ than that of juvenile cats $(1.69 \%)$ and cats with current illness were significantly more likely $(\mathrm{p}<0.001)$ to be seropositive $(6.61 \%)$ than healthy cats $(1.99 \%)$. These variations in prevalence of FeLV infection are probably related to sociocultural circumstances which determine the lifestyles and origins of the domestic cats and possibilities for interactions between infected and non-infected cats although, no significant relationship between the diseases (FInV and FeLV) and different variables were found in this study.

Table 1: Distribution of Feline Influenza (FInV) and Feline Leukemia (FeLV) infection in local breed cats of Bangladesh detected by one-step rapid Ag test kit

\begin{tabular}{|c|c|c|c|c|c|}
\hline Variables & Category level & Sample tested & $\begin{array}{c}\text { Prevalenceof FinV } \\
{[95 \% \mathrm{CI}]}\end{array}$ & $\begin{array}{c}\text { Positive result } \\
\text { for FeLV No. (\%) }\end{array}$ & Level of significance \\
\hline \multirow[t]{3}{*}{ Age } & $<2$ months & 28 & $0(0.00)$ & $0(0.00)$ & NS \\
\hline & 2 months to 1 year & 15 & $2(13.33)$ & $0(0.00)$ & - \\
\hline & $>1$ year & 17 & $1(5.88)$ & $1(5.88)$ & - \\
\hline \multirow[t]{2}{*}{ Sex } & Male & 33 & $1(3.33)$ & $0(0.00)$ & NS \\
\hline & Female & 27 & $2(7.41)$ & $1(3.70)$ & - \\
\hline \multirow[t]{2}{*}{ Health condition } & Apparently healthy & 39 & $2(5.13)$ & $1(2.56)$ & NS \\
\hline & With fever and nasal discharge & 21 & $1(4.76)$ & $0(0.00)$ & - \\
\hline \multirow[t]{2}{*}{ Type } & Pet (owned) cats & 48 & $2(4.17)$ & $1(2.08)$ & NS \\
\hline & Stray (free roaming) cats & 12 & $1(8.33)$ & $0(0.00)$ & \\
\hline
\end{tabular}

*NS $=$ Non Significant where a $p$-value of $p<0.05$ was considered significant 


\section{CONCLUSION}

Despite the fact that the sample size in this study was too small, the results of the study carry significant information about the existence of FInV and FeLV infections in cats in Bangladesh. It may be claimed as the first report on prevalence of FInV and FeLV in cats in Bangladesh since, to the best of researcher's knowledge there are no inland reports on these two diseases. In the present survey, cats had no history of vaccination against feline viral diseases. It may be suggested that cats especially pet cats should be vaccinated against these two viral diseases to protect pet cats. The knowledge of the status of FInV and FeLV in cats in the study area will be helpful for better define prophylactic, management and therapeutic measures for owned and stray cats against FInV and FeLV infection. However, further epidemiological and microbiological studies are needed for better understanding of the diseases in stray and pet cats.

\section{ACKNOWLEDGEMENTS}

The researchers would like to mention great appreciation of RapiGEN Inc. (4F 693-11, GeumjeongDong, Gunpo-Si, Gyeonggi-Do, 435-862, Korea) for donation of RapiGEN ${ }^{\circledR}$ Feline Influenza Virus (FInV) Ag test kit and RapiGEN ${ }^{\circledR}$ Feline Leukemia Virus (FeLV) Ag test kit.

\section{REFERENCES}

Addie, D.D., S. Toth, H. Thompson, N. Greenwood and O. Jarret, 1998. Detection of feline parvovirus in dying pedigree kittens. Vet. Rec., 142: 353-356.

Arjona, A., E. Escolar, I. Soto, N. Barquero, D. Martin and E. Gomez-Lucia, 2000. Seroepidemiological survey of infection by feline leukemia virus and immunodeficiency virus in Madrid and correlation with some clinical aspects. J. Clin. Microbiol., 38: 3448-3449.

Bandecchi, P., D. Matteucci, F. Baldinotti, G. Guidi, F. Abramo, F. Tozzini and M. Bendinelli, 1992. Prevalence of feline immunodeficiency virus and other retroviral infections in sick cats in Italy. Vet. Immunol. Immunopathol, 31: 337-345.

Bulter, D., 2006. Can cats spread avian flu? Nat, 440: $135-135$.

Carter, G.R., E.F. Flores and D.J. Wise, 2006. Herpesviridae. In: A Concise Review of Veterinary Virology, Carter G.R., D.J. Wise and E.F. Flores (Eds.). International Veterinary Information Service, Ithaca, USA.
Cave, T.A., H. Thompson, S.W. Reid, D.R. Hodgson and D.D. Addie, 2002. Kitten mortality in the United Kingdom: A retrospective analysis of 274 histopathological examinations (1986 to 2000). Vet. Record., 151: 497-501.

Cotter, S.M., 1998. Feline Viral Neoplasia. In: Infectious Diseases of the Dog and Cat, Greene, C. (Eds.). W. B. Saunders Company Ltd., Philadelphia, USA., pp: $71-84$.

Fromont, E., A. Sager, F. Leger, F. Bourguemestre and E. Jouquelet et al., 2000. Prevalence and pathogenicity of retroviruses in wildcats in France. Vet. Rec., 146: 317-319.

Hardy, W.D., 1980. Feline Leukemia Virus Disease. In: Developments in Cancer Research, Hardy, W.D., M. Essex and J.A. McClelland (Eds.). Elsevier Scientific Publishing Company, Amsterdam, The Netherlands, pp: 3-31.

Hardy, W.D., Jr. and J. McClelland, 1977. Feline Leukemia virus. Its related diseases and control. Vet. Clin. North Am., 7: 93-103.

Hosie, M.J., C. Robertson and O. Jarrett, 1989. Prevalence of feline leukaemia virus and antibodies to feline immunodeficiency virus in cats in the United Kingdom. Vet. Rec., 125: 293-297.

Jarrett, W.F., W.B. Martin, G.W. Crighton, R.G. Dalton and M.F. Stewart, 1964. Transmission experiments with leukemia (lymphosarcoma). Nat., 202: 566-567.

Julia, M., S. Bianka, C.H.P.D. Timm, W.V.P.D. Thomas, $H$. Janine and H. Katrin, 2008. Prevalence of influenza A H5N1 virus in cats from areas with occurrence of highly pathogenic avian influenza in birds. J. Feline Med. Surg., 10: 355-358.

Lee, I.T., J.K. Levy, S.P. Gorman, P.C. Crawford and M.R. Slater, 2002. Prevalence of feline leukemia virus infection and serum antibodies against feline immunodeficiency virus in unowned free-roaming cats. J. Am. Vet. Med. Assoc., 220: 620-622.

Levy, J., C. Crawford, K. Hartmann, R. Hofmann-Lehmann, S. Little, E. Sundahl and V. Thayeret, 2008. American association of feline practitioner's feline retrovirus management guidelines. J. Feline Med. Surg., 10: 300-316.

Little S., W. Sears, J. Lachtara and D. Bienzle, 2009. Seroprevalence of feline leukemia virus and feline immunodeficiency virus infection among cats in Canada. Can. Vet. J., 50: 644-648.

Mackenzie, D., 2007. Deadly H5N1 may be brewing in cats. New Sci., 193: 6-7.

Malik, R., K. Kendall, J. Cridland, S. Coulston, A.J. Stuart, D. Snow and D.N. Love, 1997. Prevalence of feline leukemia virus and feline immunodeficiency virus infections in cats in Sydney. Aust. Vet. J., 75: 323-327. 
Mosallanejad, B., R. Avizeh and N.M. Ghorbanpoor, 2009. Antigenic detection of Feline Panleukopenia virus (FPV) in diarrhoeic companion cats in Ahvaz area. Iran. J. Vet. Res., 10: 289-293.

Nakamura, K., Y. Ikeda, T. Miyazawa, N.T. Nguyen and D.D. Duong et al., 1999. Comparison of prevalence of feline herpesvirus type 1, calicivirus and parvovirus infections in domestic and leopard cats in Vietnam. J. Vet. Med. Sci., 61: 1313-1315.
Stephen, J.E., D.V.M. Dacvim and E.C. Feldman, 1995. Textbook of Veterinary Internal Medicine. 7th Edn., Saunders, Philadelphia, USA., ISBN-13: 9781416065937, Pages: 2208.

Sukura, A., T. Salminen and L.A. Lindberg, 1992. A survey of FIV antibodies and FeLV antigens in freeroaming cats in the capital area of Finland. Acta. Vet. Scand., 33: 9-14.

Ueland, K. and H. Lutz, 1992. Prevalence of feline leukemia virus and antibodies to feline immunodeficiency virus in cats in Norway. Zentralbl. Vet. Med. B, 39: 53-58. 